June 1992

\title{
Demystifying the Psychiatric Case Formulation
}

\author{
Len Sperry, M.D., Ph.D. \\ Medical College of Wisconsin, Milwaukee, Wisconsin
}

Follow this and additional works at: https://jdc.jefferson.edu/jeffjpsychiatry

Part of the Psychiatry Commons

Let us know how access to this document benefits you

\section{Recommended Citation}

Sperry, M.D., Ph.D., Len (1992) "Demystifying the Psychiatric Case Formulation," Jefferson Journal of Psychiatry. Vol. 10 : Iss. 2 , Article 4.

DOI: https://doi.org/10.29046/JJP.010.2.002

Available at: https://jdc.jefferson.edu/jeffjpsychiatry/vol10/iss2/4

This Article is brought to you for free and open access by the Jefferson Digital Commons. The Jefferson Digital Commons is a service of Thomas Jefferson University's Center for Teaching and Learning (CTL). The Commons is a showcase for Jefferson books and journals, peer-reviewed scholarly publications, unique historical collections from the University archives, and teaching tools. The Jefferson Digital Commons allows researchers and interested readers anywhere in the world to learn about and keep up to date with Jefferson scholarship. This article has been accepted for inclusion in Jefferson Journal of Psychiatry by an authorized administrator of the Jefferson Digital Commons. For more information, please contact: JeffersonDigitalCommons@jefferson.edu. 


\title{
Demystifying the Psychiatric Case Formulation
}

\author{
Len Sperry, Ph.D., M.D.
}

\begin{abstract}
Until recently case formulation was an ethereal art, in that there was no standard, agreed-upon format for conceptualizing and writing formulations. However, the increasing emphasis on accountability in psychiatric care, the trend toward theoretical integration, and the difficulty trainees experience in mastering formulation skills highlight the need for a standard format. The descriptive, etiological and treatment-prognostic components of a formulation are discussed as a standard format for conceptualizing and writing case formulations. Four written formulations are described in terms of content, structure and process to illustrate this format.
\end{abstract}

The psychiatric formulation is the clinician's compass guiding treatment. It should accurately reflect the patient and his or her pattern of functioning as well as the precipitants, predisposing and perpetuating factors, and prognosis, while also being clear, concise and clinically useful. Yet, the art of case formulation has been too often shrouded in a mystical aura. Largely this is because there has been no standard, agreed-upon format for conceptualizing a formulation, and seldom has it been written or required as part of a case record or documentation (1). Traditionally, developing the skill of formulating cases has been relegated to individual supervision and case conferences during psychiatric residency training (2). Unfortunately, the performance of recent graduates in formulating case material on oral psychiatry board examinations suggests these skills may be inadequate. A recent poll for the British equivalent of the $\mathrm{ABPN}$ oral examination found that 87 percent of examiners mentioned the candidates' inability to present a coherent formulation as the chief reason for failing the exam (3).

Today, the shift toward briefer and more cost-effective psychiatric treatment, as well as the trend toward theoretical integration has resulted in changes in our understanding and utilization of case formulations. The value and necessity of succinct, well-conceptualized, written case formulation has been recognized and is rapidly becoming a requirement for psychiatric evaluations, discharge summaries, and prior authorizations for treatment in both public and private sectors (2). Thus, it becomes imperative that psychiatry training programs formally and more systematically facilitate the learning and acquisition of the skill of case formulation. A standardized formulation format could greatly aid in developing and refining this essential skill.

This paper briefly describes the components of a case formulation and suggests a 
standard format for conceptualizing and writing case formulations. Four written case formulation reports for a single case are then presented. These reports reflect the structure, content and process among the current biological, psychodynamic, behavioral and biopsychosocial orientations (4-9). A side-by-side comparative analysis of these reports illustrates the utility of the format.

\section{THE ANATOMY OF A CASE FORMULATION}

Basically, there are three components of a psychiatric formulation: descriptive, etiological and treatment-prognostic (1). A descriptive formulation is a phenomenological statement about the nature, severity and precipitants of an individual's psychiatric presentation. It answers the "What happened?" question. While there are many different ways to conceptualize this data, for all practical purposes, the descriptive formulation lends itself to DSM-III-R diagnostic criteria and nosology.

An etiological formulation attempts to offer a rationale for the development and maintenance of symptoms and dysfunctional life patterns. It is more explanatory and longitudinal in nature. Etiological formulations answer the "Why did it happen?" question.

A treatment-prognostic formulation follows from the descriptive and etiological formulations and serves as an explicit blueprint governing treatment interventions and prognosis. The treatment formulation addresses the "What can be done about it and how?" question. As in the other two functional types of formulations, there might be many ways to answer this question.

A review of recent publications (4-9) indicates that cases formulated in four major orientations-biological, psychodynamic, behavioral and biopsychosocialtend to encompass all three structural dimensions: descriptive, etiological and treatment-prognostic. Parenthetically, the review also suggests some convergence in content among the varying approaches. Convergence refers to the emerging similarities among distinct orientations rather than to an actual integration or synthesis of these orientations (10).

The case of Mr. Z. describes a relatively common psychiatric presentation. It is followed by four psychiatric formulations to illustrate the process of the biological, psychodynamic, behavioral and biopsychosocial orientations. Each formulation is organized in three sections, designated I-III: Section I refers to the "descriptive" function, II refers to the "etiological" function and III to the "treatment-prognostic" function.

\section{THE CASE OF MR. Z}

Mr. Z is a 40-year-old businessman who presented with complaints of loss of interest in his job, hobbies, and family over a period of six weeks. He acknowledged periods of profound sadness, reduced appetite with significant weight loss, insomnia, fatigue, and recurrent thoughts of death, but denied suicidal ideation. He denied any precipitants but did admit that his expected job promotion had not materialized. 
Mr. Z described himself as unusually serious, conservative, and relatively unable to express affection. He also acknowledged trying to be perfect, needing to be in control of every social situation, and having an excessive commitment to work.

$\mathrm{Mr} . \mathrm{Z}$ indicated that his marriage had been worsening for several years and described his wife as flighty, overemotional and helpless under stress. For the past, several years she had been angry, distant, and had declined to be involved sexually with him. Since the onset of his symptomatology, however, she had been solicitous and obviously concerned. The Z's have two children, a boy, 12, and a girl, 10, who appeared to be doing well at school and home.

Mr. Z described his family of origin as very poor. His father deserted his mother when the patient was 12 years of age and, as the oldest child, he had to take considerable responsibility for younger siblings, as well as to work part-time while attending school. He knew that his maternal grandfather had committed suicide and that two maternal uncles were alcoholics. A paternal uncle had died in prison after a long period of antisocial behavior.

Physical, laboratory, and neurological studies were negative.

Axis I 296.22 Major Depression, single episode

Axis II 301.40 Obsessive-Compulsive Personality Disorder

Axis III No relevant current physical disorder

Axis IV 3; Moderate stress with marital discord

Axis V GAF now 50; past 12 months 69

\section{BIOLOGICAL FORMULATION}

I. This is the first psychiatric consultation for a 40 year old married male. He presents with a six-week history of profound sadness, weight loss, decreased appetite, anhedonia and recurrent depressive disorder and suicidal threat. Further information is needed about mood reactivity, the nature of the insomnia, diurnal variation, excessive guilt, psychomotor agitation or retardation, melancholic symptoms, hopelessness, and thoughts of death. Although screening physical and neurological exams and laboratory evaluations were negative, insidious medical conditions, depressogenic medications, and drug and alcohol abuse must all be ruled out. Concurrent stressors and available support systems need to be carefully assessed since such resources can reduce the impact of potential stressors.

II. Mr. Z's positive family history of suicide, alcoholism and sociopathy has genetically predisposed him to an affective disorder. Though job, marital, and family stressors have been identified, it is just as likely that they are a result rather than a cause of the depressive symptoms. Assuming there is not occult or subclinical medical condition, prescribed medication, or alcohol and drug use that is etiologic and that melancholic features are present, the diagnosis of Major Depression, single episode is established. Given Mr. Z's current cognitive style, a heightened risk for suicide is present.

III. If sufficient family support for Mr. Z's care outside a structured environment cannot be assured, inpatient hospitalization is recommended. A heterocyclic antide- 
pressant-rather than a MAOI or psychotherapy - would be the treatment of choice, monitored by a psychiatrist well-experienced with psychopharmacology. If the insomnia was of the initial type, a more sedating drug like imipramine, trazadone or maprotiline would be tried first. The patient and his relatives would be educated about the depressive disorder, its prognosis, and the therapeutic and side effects of the medication. This education would include a discussion of the anticipated therapeutic effect, the estimated duration of treatment, and the importance of compliance with medication and follow-up appointments. Scheduled weekly visits, with phone calls as needed, would be set for the first two months. Sessions would be changed to bimonthly and then monthly, assuming adequate response and resolution of symptoms. In the unlikely event that only a partial response was achieved after 4 to 6 weeks, drug plasma levels would be drawn and the dose would be adjusted. If no improvement in symptoms occurred, triiodothyronine, $25 \mathrm{mcg} / \mathrm{day}$, would be added. If a noticeable response still had not occurred, a protocol for treatment-resistant depression would be followed. Given that Mr. Z's mood disorder had sufficiently improved, the need for concurrent psychotherapy would be assessed. Drug maintenance would continue for at least six months after a full remission of symptoms. This would be at approximately $50-75 \%$ of the therapeutic dose. Subsequently, the dosage would be further tapered and then discontinued if possible.

\section{PSYGHODYNAMIC FORMULATION}

1. The patient is a 40-year-old married businessman who presented for evaluation and treatment after being passed over for promotion about eight weeks prior to evaluation. Since then he notes dysphoria, anhedonia, and vegetative symptoms of depression. He also reports a recurring thought to run off and be free of demands, and a nightmare in which he experienced a profound dread of being far away and lost. His father was described as tyrannical, critical, and unsuccessful as a businessman, while mother was overprotective and intrusive. She worked, and though she did not date or remarry, lead an active social life after her husband abandoned the family when the patient was 12. Mr. Z appears to meet criteria for a diagnosis of Major Depressive Episode. His family history is positive for chronic depression as well as alcohol dependence, suicide and antisocial behavior suggesting the possibility of a genetic predisposition for major psychopathology, specifically for unipolar depression. Mr. Z is in the latter stage of adult "settling down" or the beginning of mid-life, bringing with it the perception that one has a limited future and highlighting the increased importance of stability and progression occupationally and enduring intimate and social relationship. Stressors such as marital and family difficulties as well as being passed over for promotion could be noteworthy narcissistic injuries which could further predispose Mr. Z toward clinical depression.

II. Mr. $\mathrm{Z}$ appears to have a central conflict between a need to be perfect and in control, and an underlying image of himself as weak, imperfect, and lonely. $\mathrm{He}$ recognizes in himself a mild degree of anger toward superiors and peers, but has never expressed this. He internalized his mother's expectations, but harbors substan- 
tial anger at her over-intrusive demands and pushes aside the issue of father. He frequently looked for support from male teachers but seldom found a mentor. He experiences a good deal of self-doubt, but hides this effectively at work. Falling in love and early marriage was clearly a positive time, although he often has wanted to control the marriage.

The patient's depression can be understood in terms of his underlying profound disappointment in himself, his fear of failure in his mother's eyes, inability to gain attention from the boss, and fear of exposure to his wife. The conflict between a need to prove himself and his fear of inadequacy, dependency and loss of control is central. The ages of his children reinforce a fantasy that to leave is a solution which he experienced with his father. Primary defenses include repression, regression, introjection, intellectualization and isolation of affect.

III. Intervention with an antidepressant medication such as fluoxetine is the preferred initial treatment. However, it can be anticipated that Mr. Z will experience difficulty with control, dependence on medication, and acceptance of his illness. He may be guarded, scrupulous, querulous, overconscientious and obstinate. He is likely to become distrustful of the therapist and fear he is controlled, and underlying conflicts and transference reactions will emerge as a part of medication management.

The patient may attempt to elicit support from the therapist especially if the therapist is male. Initially, he may be ingratiating and superfically compliant, but soon Mr. Z may engage the therapist in competitive struggles and may well see him as uncaring, as was the situation with his father. Hence, a devaluation of the therapeutic process may develop, where any suggestions or recommendations by the therapist may be met with disdain. Thus, the therapist will need to be attuned to the patient's need for a relationship, and simultaneous fear of intimacy. The therapist must be active with the patient, yet respect both the necessary distance and fundamental feelings of intrusion which this patient will experience.

\section{BEHAVIORAL FORMULATION}

I. At the age of $40, \mathrm{Mr} . \mathrm{Z}$ is experiencing his first episode of major depressive disorder. There is probable evidence for an Axis II diagnosis of obsessive-compulsive personality disorder. Mr. Z has experienced a profound change in his behavior over a six-week period manifested by markedly reduced environmental interactions within a range of social stimuli (job, hobbies, family), by cognitive distortions (sadness, recent thoughts of death), and by altered physiological behaviors (sleep, appetite, energy level). The two major clinical hypotheses are that a change in work status (failure to be promoted) and a loss of source of personal reinforcement (decreased marital satisfaction) were sufficient to elicit the expression of depressive symptoms.

II. Being passed over for promotion and the loss of personal reinforcement appear to have precipitated a number of negative schemas. These are amplifications of preexisting learned behavior and cognitive patterns (restricted emotional responsivity, negative cognitive set, excessive expectations) as well as an innate genetically determined vulnerability to loss of environmental reinforcers (maternal grandfather 
committed suicide) and maladaptive familial patterns of behavior, possibly secondary to alexithymia (alcoholism and sociopathy in family members).

III. Treatment planning would include cognitive strategies to recognize and diminish negative schemas or cognitions and develop or increase positive attributions and interactions. Relaxation training and distraction procedures would be undertaken to help secure sound sleep and diminished nocturnal rumination. The central theme to treatment planning would be to help Mr. Z reestablish control over his own thinking. Homework would be assigned to reinforce these activities after they had been modelled in the office. Also included would be an exercise regimen with daily quotas. Specific hypotheses would be formulated and tested by having the patient gather and record data (for example, improvement in mood following exercise or the ability to disrupt nocturnal rumination).

The marital situation would be explored further based on the observation that the recent change in his wife's responses is more likely to reinforce helplessness and maladaptive sick role behavior than a healthy interaction and normal sex life. If appropriate, couples therapy would be suggested to modify these interactions. In view of the biological features of illness, treatment with medication would be suggested but acceptance would depend on the patient's attributions and beliefs about the appropriateness of medication and its possible efficacy. The patient's high need for control might well create a reluctance to take drugs although, if initiated, compliance would probably be excellent. Concurrent drug and behavioral treatment could be synergistic and beneficial.

The immediate prognosis would be excellent, based on the fact that this is a first episode in an individual with high levels of achievement. Mr. Z's personality style will be conducive to strong collaboration in therapy based on a need to mastery. The prognosis for the marriage would be less certain, based on the wife's possible preference for her husband in his depressed state.

\section{BIOPSYCHOSOCIAL FORMULATION}

I. Mr. Z is a 40-year-old married businessman whose depressive-like symptoms began shortly after being passed over for a promotion. Other stressors appear to be chronic marital and sexual problems and the fact that his two children are nearing the age of independence and the age when he experienced a significant trauma in his own life, i.e., the desertion by his father when he was 12 . Although there is a positive family history for alcoholism, suicide and sociopathy, Mr. Z denies other psychiatric symptoms or treatment for himself. Mr. Z's family history of alcoholism, suicide, and sociopathy makes it likely that he has a genetic predisposition for affective illness. He appears to have major conflicts over dependency and autonomy. Because of his earlier experience with significant loss, the withdrawal of attention and affection by Mr. Z's wife and the growing independence of his children represent significant precipitating events. Mr. $\mathrm{Z}$ has considerable difficulty expressing emotions and affection. He is controlling and perfectionistic. His cognitive style is obsessive-compulsive. His primary defenses are repression, regression, introjection, isolation of affect, and intellectualization. Mr. Z's sociocultural background has helped to instill in him a 
basic belief in the value of hard work, stoicism and self-reliance with little dependence on extra-familial sources of support. From a young age, he has been reinforced to sacrifice himself and to maintain the role of provider and nurturer to others who have depended upon him for support. $\mathrm{Mr}$. $\mathrm{Z}$ is also distant from his family of origin and his current life centers around his immediate family. His role has been as a provider to a wife and children who have been dependent upon him. Mr. Z and his wife have not been able to form a satisfactory marital coalition, they do few things together, and their sexual relationship has deteriorated. His wife had withdrawn emotionally and sexually from him until his recent problems, which promoted her attention and concern. Mr. Z has been able to adapt fairly well educationally and occupationally, and is a successful businessman. However, he has limited social relationships, no close friends, and few independent recreational activities.

II. Mr. Z's probable biological predisposition to affective instability, coupled with the abandonment by his father and familial and sociocultural reinforcement, resulted in the development of a rigid, obsessive-compulsive personality. His role evolved into one of stoic, hard-working, self-sacrifice in the service of others who are dependent upon him and a denial of his own dependency needs. While adaptive educationally and occupationally, his personality structure and ego defenses resulted in an isolated lifestyle and the inability to acknowledge his own feelings or to relate to others with warmth and affection. The symbolic abandonment by his wife and children reawakened old dependency conflicts, threatened his adaptive role in life, overwhelmed his rigid defenses, and resulted in anxiety, regression, and depression.

III. A problem list includes 1) clinical depression; 2) marital discord including sexual difficulties; 3) an obsessive-compulsive style; 4) limited social support system with friends; and 5) limited recreational activities. Initial treatment will include an antidepressant and supportive psychotherapy evolving to insight-oriented treatment as depressive symptoms abate, possibly in a group format. Couples therapy including work on sex issues could also be initiated after symptom amelioration. Finally, the patient will be aided in increasing his support system and recreational activities.

Since this is a single, discrete episode of depression in a person with good pre-morbid functioning, the prognosis for a return to a baseline level is good. It is likely that Mr. Z's depressive symptoms will respond to medication. His obsessive compulsive personality disorder and unmet dependency needs are longstanding problems with a more guarded prognosis that depends on his ability to engage in effective psychotherapy and to expand and modify his range of contacts and activities. The prognosis for his marriage is also guarded and depends upon the willingness of his wife and himself to examine their relationship, explore new avenues of interaction, and modify their roles. Marital therapy will likely be required to accomplish these goals.

\section{DISCUSSION}

Although there are some differences in emphasis in the formulations of the case of Mr. Z, a side-by-side comparison shows similarities in structure, content and 
process of the four reports. Structurally, each orientation includes descriptive, etiological, and treatment-prognostic functions.

An examination of the content in each section of the four orientations shows differences in emphasis but also striking similarities. Each orientation recognizes the importance of data in all three of the biological, psychological, and social spheres; arrives at a diagnosis compatible with DSM-III-R; advocates intervention with medications as well as some type of psychotherapy; and attempts to predict the possible outcome of treatment.

An examination of process of the four formulations likewise shows differences in emphasis as well as similarities. Each formulation moves in sequence from a statement of the pertinent data, to an attempt to explain the meaning of the data, and finally to recommend specific treatment based upon that understanding. Each formulation attempts to identify symptoms and to orchestrate their treatment in a manner consistent with its view of psychopathology.

The written case formulation is becoming a requirement in clinical practice. This paper has argued that an effective case formulation has three components: diagnostic, etiological and treatment-prognostic, and that the literature (4-9) suggest these components are common in the way current biological, psychodynamic, cognitive-behavioral, and biopsychosocial formulations are conceptualized and written. Finally, side-by-side comparison of the four Mr. Z case formulations illustrate the utility of this format. It is hoped that the proposed format will demystify case formulations and aid psychiatry residents in conceptualizing and writing more effective psychiatric case formulations.

\section{REFERENCES}

1. Sperry LT, Gudeman JE, Blackwell B, Faulkner LR: Psychiatric case formulations. Washington, DG: American Psychiatric Press, 1992

2. Sharfstein SS, Beigel A (eds): The new economics and psychiatric care. Washington, DC: American Psychiatric Press, 1985

3. Reveley A: Why do candidates fail the MRC Psych Part II? Bull of Royal College of Psychiatrists 1983; 5:51

4. Rabkin J, Klein D: The biological therapies. In Treatment Planning in Psychiatry. Edited by Lewis J, Usdin G, Washington, DC, American Psychiatric Press, pp. 89-150, 1982

5. Perry S, Cooper AM, Michels MD: The psychodynamic formulation: Its purpose, structure and clinical application. Am J Psychiatry 1987; 144:543-550

6. Turkat ID, Wolpe, J: Behavioral formulation of clinical cases in I.D. Tarkat (ed.) Behavioral Case Formulations. New York: Harper and Row, 1988

7. Faulkner LF, Kinzie JD, Angell R, Uren RC, Share JH: A comprehensive psychiatric formulation model, J Psychiatric Educ 1985; 9:189-203

8. Persons JB: Cognitive Therapy in Practice: A Case Formulation Approach. New York: Norton, 1989

9. Lazare A: A multidimensional approach to psychopathology, in Lazare, A (ed.) Outpatient Psychiatry: Diagnosis and Treatment. Second Edition. Baltimore: Williams and Wilkins, 1989

10. Beitman BD, Goldfriend MR, Norcross JC: The movement toward integrating the psychotherapies: An overview. Am J Psychiatry 1989; 146:138-147 